\title{
Ultrasonography of the Lung
}

\section{Ultraschall der Lunge}

Authors

Maija Radzina', 2, 3, Jürgen Biederer 3, 4, 5, 6

Affiliations

1 Riga Stradins University, Radiology Research Laboratory, Riga, Latvia

2 Paula Stradina Clinical University Hospital, Diagnostic Radiology Institute, Riga, Latvia

3 University of Latvia, Faculty of Medicine, Riga, Latvia

4 Department of Diagnostic and Interventional Radiology, University Hospital of Heidelberg, Heidelberg, Germany

5 Translational Lung Research Center Heidelberg (TLRC), Member of the German Lung Research Center (DZL), Heidelberg, Germany

6 Christian-Albrechts-Universität zu Kiel, Faculty of Medicine, Kiel, Germany

Key words

thorax, ultrasound, pleura, pneumonia, lung

received 24.10 .2018

accepted 27.02.2019

Bibliography

DOI https://doi.org/10.1055/a-0881-3179

Published online: 4.4 .2019

Fortschr Röntgenstr 2019; 191: 909-923

(c) Georg Thieme Verlag KG, Stuttgart · New York

ISSN 1438-9029

Correspondence

Prof. Jürgen Biederer

Abteilung Diagnostische und Interventionelle Radiologie, Universitätsklinikum Heidelberg, Im Neuenheimer Feld 110, Universitätsklinikum Heidelberg, 69120 Heidelberg, Germany Tel.: ++49/62 21/5635649

Fax: ++ 49/6221/565730

juergen.biederer@uni-heidelberg.de

\section{ZUSAMMENFASSUNG}

Hintergrund Eine hohe diagnostische Treffsicherheit, zunehmende klinische Erfahrung und technische Verbesserungen machen den Ultraschall der Lunge zu einer interessanten Alternative für die Untersuchung pleuraler und pulmonaler Erkrankungen. Im Schockraum und auf der Intensivstation ist der Ultraschall etabliert. Ziel dieses Artikels ist, weitere potenzielle Anwender in der Radiologie mit der diagnostischen Reichweite der Methode vertraut zu machen und zu einer breiteren Anwendung dieses in der thorakalen Bildgebung häufig unterschätzten Verfahrens anzuregen.
Methode Die Literaturrecherche erfolgte in der Datenbank MEDLINE (via PubMed) im Suchzeitraum von 2002 bis 2017 mittels Freitext- und Schlagwortsuche (Medical Subject Headings/MeSH) durch 2 unabhängige Reviewer. Die Auswahl der Artikel erfolgte im Konsensus entsprechend Relevanz und Evidenzgrad.

Ergebnisse und Schlussfolgerung Die technischen Voraussetzungen sind mit einem modernen Ultraschallgerät und einem geeigneten Schallkopf erfüllt. Während Pathologien der Thoraxwand und der Pleura (z. B. Pleuraerguss) im B-Bild gut erkennbar sind, erfolgt die Beurteilung der pulmonalen Pathologie jenseits der Pleuralinie meist indirekt anhand typischer Artefakte und Zeichen. Diese erlauben z. B. die Unterscheidung von hämodynamischem Lungenödem, Pneumonie, Lungenembolie, exazerbierter COPD/Asthma oder Pneumothorax. Standardisierte Zugangswege und eine exakte Terminologie tragen wesentlich zur diagnostischen Genauigkeit und Reproduzierbarkeit der Methode auch in anspruchsvollen Situationen und bei erschwerten Untersuchungsbedingungen bei. Im Schockraum erlaubt der Lungen-Ultraschall eine sichere und schnelle Identifizierung des interstitiellen Lungenödems bei Patienten in Atemnot. Beim ambulanten Einsatz erlaubt die Sonografie eine schnelle und sichere Differenzierung von Pleuraerguss, Pleuritis und Pneumonie. Nicht zuletzt die Reduzierung der diagnostischen Strahlenexposition spricht für einen breiteren Einsatz dieser häufig unterschätzten Methode als kosten-, zeit- und strahlensparende Alternative oder als wertvolle Ergänzung zu den etablierten Standardverfahren.

\section{Kernaussagen:}

- Der Lungen-US ist eine einfach verfügbare, sichere Methodik mit Optionen zur dynamischen Beurteilung der Atemmechanik.

- Eine an die Fragestellung angepasste Untersuchungstechnik und die standardisierte Beschreibung und Interpretation typischer Zeichen und Artefakte in Zusammenschau mit der klinischen Fragestellung bestimmen die diagnostische Sicherheit.

- Bei Dyspnoe lassen sich Pneumothorax, Lungenödem, Pneumonie, Lungenembolie, Atelektasen und Pleuraergüsse differenzieren.

- Lungenventilation und Infusionstherapie lassen sich mittels Lungen-US steuern.

- Bei Verlaufskontrollen, Schwangerschaft und Kindern wird eine Strahlenexposition vermieden. 


\section{ABSTRACT}

Background High diagnostic accuracy, increasing clinical experience and technical improvements are good reasons to consider lung ultrasound (US) for the assessment of pleural and pulmonary diseases. In the emergency room and in intensive care, it is well acknowledged, but application in other settings is rare. The aim of this review is to update potential users in general radiology about the diagnostic scope of lung US and to encourage more frequent use of this generally underestimated lung imaging modality.

Method Literature review was done independently by the two authors in MEDLINE (via PubMed) covering a time span from 2002 until 2017 using free text and Medical Subject Headings/MeSH. Article selection for the bibliography was based on consensus according to relevance and evidence.

Results and Conclusion The technical prerequisites include a standard ultrasound unit with a suitable transducer. Pleural effusion and pneumothorax, atelectasis, interstitial edema, pneumonia, exacerbated chronic obstructive pulmonary disease/asthma and pulmonary embolism can be distinguished by particular ultrasound signs, artifacts and their combinations. A highly standardized selection of access points and terminology for the description of imaging findings contributes to high diagnostic accuracy even in challenging patients and settings. Besides the assessment of acute respiratory failure in the emergency room, lung US may be used for monitoring interstitial fluid accumulation in volume therapy and for the diagnosis of pneumonia or the assessment of pleural effusion and pleurisy in a routine outpatient setting. Last but not least, the increasing concerns about medical radiation exposure warrant a more extensive use of this sometimes underestimated modality as a cost-, time- and radiation-saving alternative or valuable adjunct to the standard imaging modalities.

\section{Key Points:}

- Lung US is a safe, quick and readily available method with options for dynamic imaging of respiratory function.

- Proper selection of technical parameters customized to the clinical question and standardized terminology for the precise description and interpretation of the imaging signs regarding patient history determine its diagnostic accuracy.

- In dyspnea lung US differentiates pneumothorax, lung edema, pneumonia, pulmonary embolism, atelectasis and pleural effusion.

- In intensive care, lung US allows monitoring of lung ventilation and fluid administration.

- It saves radiation exposure in serial follow-up, in pregnancy and pediatric radiology.

\section{Citation Format}

- Radzina M, Biederer J, Ultrasonography of the Lung. Fortschr Röntgenstr 2019; 191: 909-923

\section{Introduction}

The workhorses for thoracic imaging in diagnostic radiology are chest X-ray, computed tomography (CT) and only more recently also magnetic resonance imaging (MRI). Traditionally, general radiologists are reluctant to use lung ultrasound due to the apparent imaging limitation of the lung tissue complex air-filled microarchitecture. The ultrasound waves cannot propagate straight through the tissue due to multiple scattering. Their linear relationship between propagation time and distance is lost, the backscattered signal is distorted and conventional imaging reconstructed from these data produces no clear images [1]. Therefore, ultrasound is not typically considered a routine imaging modality for the lung. Nevertheless, it is well acknowledged that diaphragmatic paralysis or any pathologic fluid accumulation in the pleura and/or lung can be easily visualized with conventional US imaging [2]. Furthermore, air filling of the pleural cavity results in a drastic change in impedance from tissue to air with no available imaging data from behind the visceral pleura [3], which makes ultrasound highly sensitive for the detection of even subtle pneumothorax [4]. Due to its excellent diagnostic accuracy for pleural effusion and pneumothorax, ultrasonography is implemented in the algorithms for severely injured/critically ill patients [4-6]. However, beyond imaging the pleural space, any conditions changing fluid content, impedance or inflation of the lung tissue itself alter the back-scattered ultrasound signal. Typical appearances of artifacts allow differentiation of a number of important conditions, such as interstitial lung disease, lung congestion, lung edema, consolidation and infiltration [7]. Even application during surgery in situations of unclear cardiorespiratory instability and suspected pneumothorax is considered [8]. Moreover and beyond the bedside setting, ultrasonography has been discussed as a first-line modality for the diagnosis and follow-up of community-acquired pneumonia and other indications [9]. Standardized procedures are focused on the relevant anatomical regions in the chest and well defined criteria with known sensitivity and specificity for the underlying condition allow for a fast and efficient application of the technique [10]. In the current literature, broader application and more comprehensive use of lung imaging with ultrasound is advocated $[10,11]$. It is therefore the aim of this review article to make potential users more familiar with the technical and diagnostic aspects and to encourage the more widespread application of this frequently underestimated lung imaging modality.

\section{Methods}

Literature review was performed independently by the two authors in MEDLINE (via PubMed) covering a time span from 2002 to 2017 using free text and Medical Subject Headings/MeSH. The search terms included "ultrasonography of the lung", "ultrasound of the lung", "ultrasound of pleural disease" and a selected search for "ultrasound of pneumonia", "pleural effusion", "chest ultrasound", etc. Article selection for the bibliography was based on 


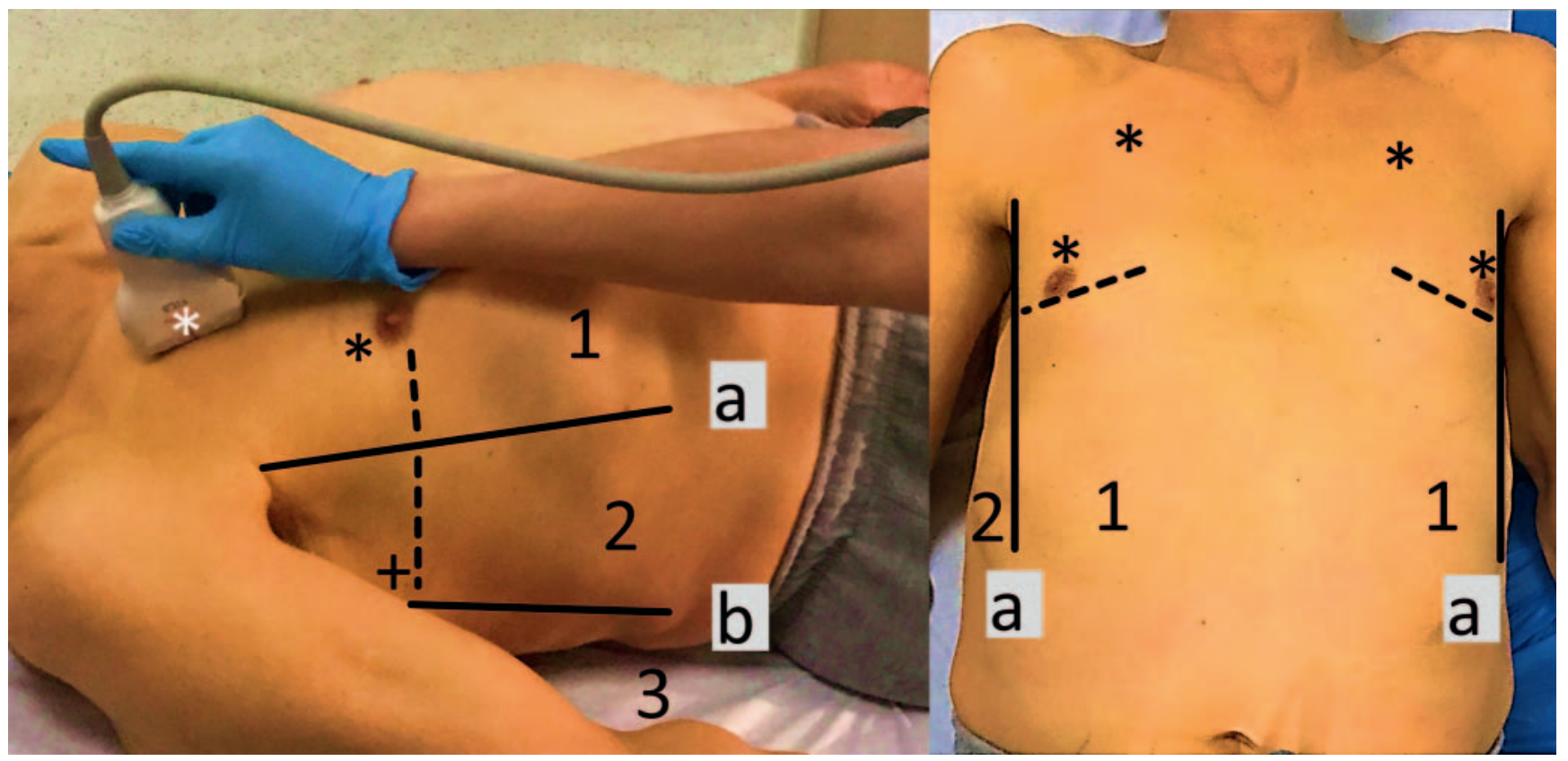

- Fig. 1 Transducer positions for a lung ultrasound examination in the recumbent patient (a: anterior axillary line, b: posterior axillary line, 1 - 3 : anterior, lateral and posterior scanning zones (each divided into upper and lower part by the dotted line), asterisks: upper and lower BLUE points (on the left image the transducer is placed on the upper BLUE point), plus-sign: PLAPS point). A complete examination covers all three zones at each side scanned in the upper and the lower part [14]. The abbreviated examination covers the two BLUE points and the PLAPS point on both sides (for the detailed description, how to localize BLUE and PLAPS points see [10]).

- Abb. 1 Schallkopfpositionen für die Ultraschalluntersuchung der Lunge am liegenden Patienten (a: vordere Axillarlinie, b: hintere Axillarlinie, 1 - 3: vorderer, lateraler und hinterer Untersuchungsbereich (jeweils durch die gestrichelte Linie in einen kranialen und einen kaudalen Abschnitt geteilt), Sterne: oberer und unterer BLUE-Punkt (auf dem linken Bild ist der Schallkopf am oberen BLUE-Punkt aufgesetzt), Plus-Zeichen: PLAPS-Punkt). Die vollständige Untersuchung deckt auf beiden Seiten des Thorax alle drei Bereiche jeweils im kranialen und kaudalen Abschnitt ab [14]. Die verkürzte Untersuchung deckt die beiden BLUE-Punkte und den PLAPS-Punkt jeweils auf beiden Seiten ab (zur Lokalisation der BLUE- und PLAPS-Punkte siehe [10]).

consensus according to relevance and evidence. Levels of evidence as far as mentioned in this article refer to the international evidence-based recommendations for point-of-care ultrasound published in 2012 [6].

\section{Technical requirements}

Depending on the situation and the setting, different conditions and prerequisites must be met for ultrasound equipment. Suitable transducers for lung ultrasound are a convex, micro-convex or phased array probe for deeper structure visualization (bandwidth range $1-6 \mathrm{MHz}$ ) and a linear probe for superficial structures and pathology detection, e.g. pneumothorax (bandwidth range $3-18 \mathrm{MHz}$ ) [12]. For quick and easy bedside access, a portable or handheld unit with a micro-convex probe may be used (evidence level B) [6]. In particular for emergencies, a fast startup time of the system is advisable. Preset protocols should be available to obviate the need for time-consuming protocol adaption on-site. Further criteria are handling issues (compact portable or handheld unit, easy to clean) [10].

\section{Scanning technique}

If possible, the examination should be performed in the upright seated patient (or at least 45 degrees), allowing for access to the posterior recesses. Otherwise, the standard scanning position is supine at rest with the patient tilted to the opposite side of interest, if necessary. Access is acquired through the intercostal spaces. Limitations are defined by the bones of the chest wall and heart. Furthermore, lesions located deep inside the lungs covered by layers of healthy aerated tissue are not accessible. This includes the lung areas adjacent to the paravertebral space as well as the mediastinum [13].

Different scanning techniques adapted to the clinical setting are advocated in the literature. A complete lung examination (standard of reference) covers 12 imaging regions, 6 on each side $[10,14]$. For this, each hemi-thorax is divided into anterior, lateral, and posterior zones by the anterior and posterior axillary lines. Imaging is performed in the upper and lower part of each of these regions ( $\triangleright$ Fig. $\mathbf{1}$ ). In the recumbent critically ill, placing the arm across the chest facilitates access to the posterior zone [14]. As an extension to this protocol, a 28-site scanning technique has been suggested for a semi-quantitative assessment of pulmonary congestion over multiple intercostal spaces $[6,15]$.

Useful abbreviations of this protocol are recommended for specific clinical questions and emergency situations with time constraints. The most common approach on international consensus e.g. for lung interstitial syndrome and pulmonary edema or pneumothorax omits the posterior scan regions and uses only 


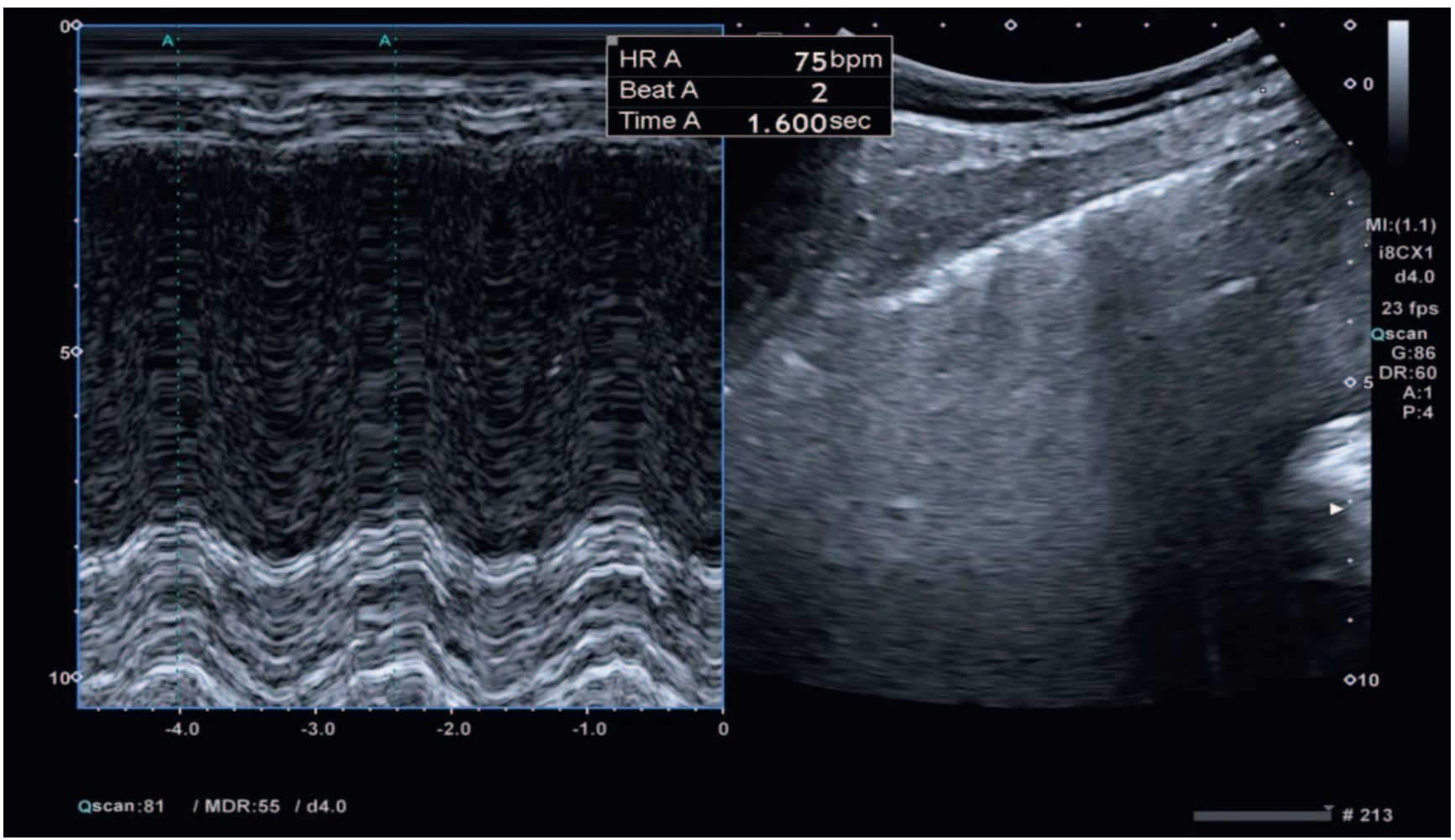

- Fig. 2 Documentation of respiratory motion in M-mode (lung sliding).

- Abb.2 Dokumentation von Atembewegungen im M-Bildmodus (Pleuragleiten).

the anterior and posterolateral chest wall approaches in supine position, resulting in an 8-zone scanning technique $[6,10]$. A further abbreviated protocol uses only 6 scanning positions, including only two anterior and one posterolateral position on each side $[6,10]$. In the literature, the two anterior scanning positions have been addressed as BLUE points (BLUE = bedside lung ultrasound in emergency) and the lateral as the PLAPS point (posterolateral alveolar and/or pleural syndrome) ( $\triangleright$ Fig. 1) [10]. A simplified approach for the quick detection of BLUE and PLAPS points in the emergency setting using the palm width and the finger length of the sonographer has been described by Lichtenstein [10]. Any protocols that do not cover the posterolateral scan regions have only limited indications, e. g. monitoring interstitial lung edema, since they will not allow for efficient assessment of pleural effusion and posterior atelectasis [6].

\section{Chest wall}

In the healthy subject, B-mode lung ultrasound produces clear images of the chest wall structures (ribs, intercostal space, sub-pleural fat layer) until the marked change of impedance at the pleural surface. All relevant structures for respiratory mechanics, including the diaphragm, can be clearly visualized. The motion of the chest wall and diaphragm can be followed in B-mode and documented in M-mode, e.g. for the assessment of chronic obstructive lung disease (see below) or phrenic nerve lesions with diaphragmatic paralysis ( $\bullet$ Fig. 2 ) $[2,16]$.

\section{Normal findings in pleura and lung, terminology}

The interpretation of lung ultrasound is based on a set of imaging signs which alone or in combination are highly sensitive and specific for a number of normal and pathologic conditions (diagnostic accuracy between $90 \%$ and $100 \%$ ). In the healthy subject, a large proportion of the ultrasound waves is reflected at the pleural line due to the differences in velocity and acoustic impedance between normal tissue and air-filled parenchyma (lung, airways, etc.). Hence, the pleural line is marked by a bright signal. The following space between the pleural signal and the bottom of the image is called Merlin's space [10]. It contains a homogeneous, structureless signal from back-scattering of ultrasound waves by healthy aerated lung tissue. Superimposed on this background, a single line or multiple lines parallel to the pleural line and perpendicular to the ultrasound beam can be observed. They are reverberations resulting from multiple reflections of ultrasound waves between the pleural line and the surface of the transducer [14]. In the previous literature, this artifact was referred to as "A-lines", but this term has been omitted on the occasion of the international point-of-care lung ultrasound consensus publication since it is not specific for any condition (these lines appear in the regularly aerated lung tissue as well as in pneumothorax) [6], ( $\triangleright$ Fig. 3a). However, the absence of horizontal reverberations may help to detect pathology in the lung (such as pulmonary ede$\mathrm{ma}$ ), but it requires dedicated interaction of the ultrasonographer to optimize their visualization before their absence can be confirmed. 


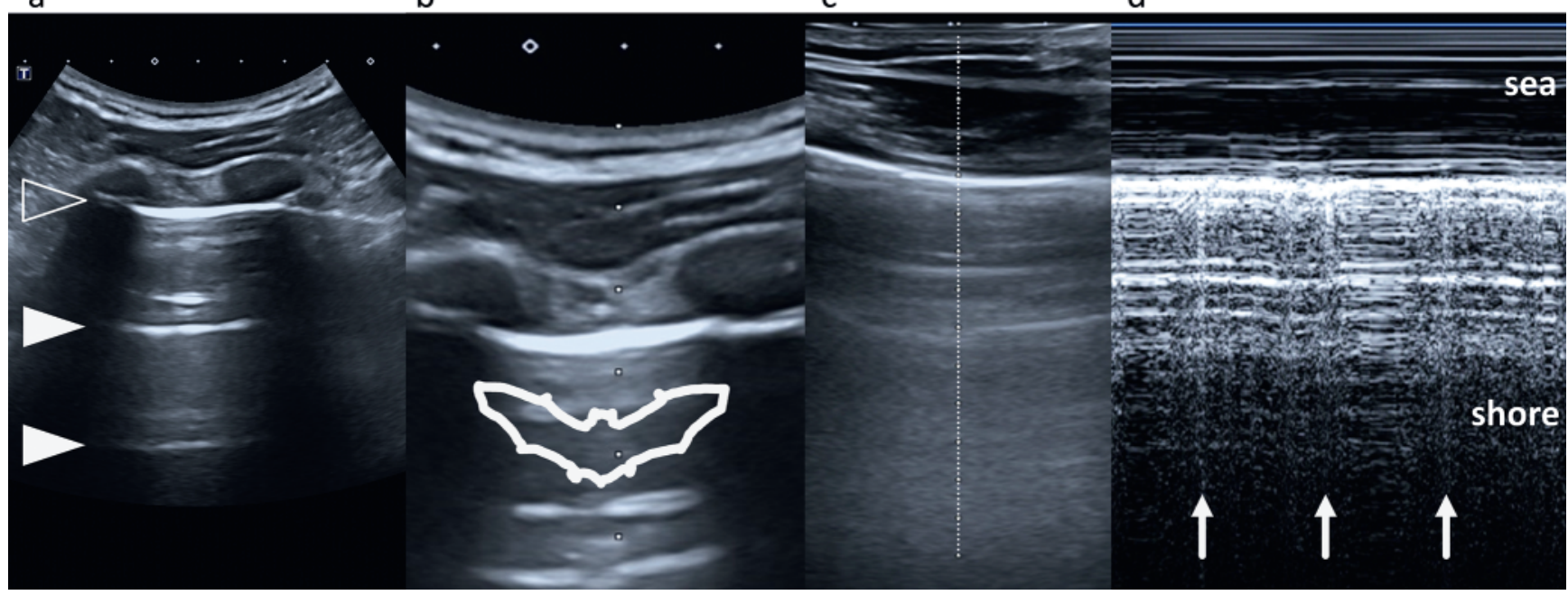

- Fig. 3 Normal and physiologic findings on lung US. a Pleural line (transparent arrowhead) and A-lines (filled arrowheads) in the healthy lung. b To imagine the outline of a flying bat may help to identify the pleural line between two ribs in difficult imaging conditions ("bat sign"). c B-mode image, the dotted vertical midline indicates the position from which the $\mathrm{M}$-mode recording in $\mathbf{d}$ was obtained. The M-mode image shows the "seashore sign" with speckled appearance of the aerated lung beyond the pleural line, resembling a sandy beach with waveform lines above it from the thoracic wall resembling sea waves. Super-imposed short vertical scatter bands reflect propagation of normal cardiac pulsation at the patient's heart rate (“lung pulse sign", arrows).

- Abb. 3 Normale und physiologische Befunde im Ultraschall der Lunge. a Pleuralinie (transparente Pfeilspitze) und A-Linien (weiße Pfeilspitzen) bei gesunder Lunge. b Bei schwierigen Schallbedingungen kann das Bild einer Fledermaus die Identifikation der Pleuralinie erleichtern („Fledermauszeichen“). c Die gepunktete Linie im B-Bild markiert die Position, von der das M-Bild in d abgeleitet wurde. Das M-Bild zeigt ein Muster, das an einen Sandstrand (feinkörniger Aspekt der belüfteten Lunge jenseits der Pleuralinie) und Meereswellen (Reflexionen der Thoraxwand) erinnert („seashore sign“). Diesem Muster sind pulssynchrone vertikale Artefakte (Pfeile) überlagert, die den fortgeleiteten Herzbewegungen des Patienten entsprechen („Lungenpuls“/,lung pulse sign“).

The "bat sign" is a helpful feature for the recognition of the pleural line even in difficult scanning conditions (patient motion, subcutaneous fat). It can be seen with the transducer in rectangular position to the ribs. The reflections from the ribs look like the wings of a bat while the back of its body is outlined by the parietal pleura [17] ( $\triangleright$ Fig. 3b).

For the exclusion of air inside the pleural layers, additional signs such as "lung sliding" need to be confirmed. Inspiration and expiration result in a lung volume change and consequently sliding of the visceral pleural surface in relation to the parietal pleura and chest wall. This movement appears as a homogeneous twinkling (shimmering, sparkling or glittering) below the pleural line $[10,14]$. The presence of this sign indicates preserved lung ventilation, direct contact of the visceral pleura to the parietal pleura and therefore the absence of pneumothorax [18]. A reduced or absent lung sliding sign may indicate hypoventilation, e. g. due to low tidal volume ventilation, or regional hypoventilation in obstructive lung disease [14]. However, it may become less visible when the ultrasound beam is tangential rather than perpendicular to the pleural surface [14]. Another sign of preserved lung physiology is the lung pulse sign, also referred to as "T-lines" ( $\triangleright$ Fig. $\mathbf{3 c}$ ). It results from relative motion of the pleura due to propagated motion from cardiac pulsations [14].

For documentation of lung sliding with printed images, $\mathrm{M}$-mode recordings in the healthy subject show the stationary extrapleural structures and a speckled appearance of the aerated, moving lung beyond the pleural line. As this image resembles calm waters (extrapleural structures) washing on the speckled sandy beach (Merlin's space), it was given the name "seashore sign" [14] ( Fig. 3d).

\section{Pleural disease}

As already mentioned, lung US is highly sensitive for any pathology that affects the marked change of impedance at the pleural surface - i. e. pleural effusion or pneumothorax [7].

\section{Pleural effusion}

With the transducer in rectangular position to the ribs, pleural effusion appears in a quadrangular space defined by the pleural line (chest wall), the shadows of the ribs and the lung line (visceral pleura) - also called "quad sign". If the effusion contains free, non- organized liquid, the distance between the pleural line and lung line decreases in inspiration due to the increased volume of the chest and increases in expiration - "sinusoid sign" [17]. It correlates to the viscosity of the pleural fluid, i.e. for the choice of the needle size for drainage. In malignant pleural effusion, pleural nodules according to metastatic growth can be easily detected ( $\triangleright$ Fig.4). In outpatients with acute chest pain, pleural ultrasound suggests the diagnosis of acute pleurisy when showing pleural thickening and minimal effusion [19]. 


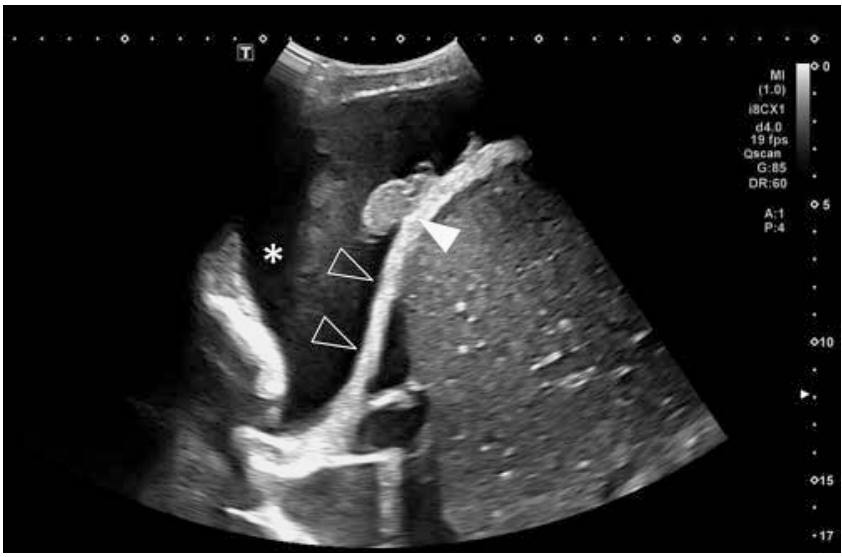

- Fig. 4 Malignant pleural effusion (asterisk) in a 30-year-old male patient with history of malignant melanoma and progressive shortness of breath. The pleura adjacent to the diaphragm appears thickened (transparent arrowheads) with adherent nodular structures related to metastatic growth (filled arrowhead).

- Abb. 4 Maligner Pleuraerguss (Stern) bei einem 30 Jahre alten Patienten mit malignem Melanom und zunehmender Kurzatmigkeit. Die zwerchfellnahe Pleura erscheint verdickt (transparente Pfeilspitzen) mit anheftenden nodulären Formationen als Korrelat pleuraständiger Filiae (weiße Pfeilspitzen).

\section{Pneumothorax}

Air inside the pleural cavity completely reflects the ultrasound waves at the pleural line with no available imaging data from the visceral pleura and deeper [3]. Lung sliding/pleural sliding therefore cannot be observed. Its absence has a sensitivity of $95.3 \%$, specificity of $91.1 \%$, and negative predictive value of $100 \%$ $(p<0.001)$ for pneumothorax with a low false-positive rate [18]. In M-mode, the absence of motion results in a static pattern of horizontal lines ("stratosphere sign") which replaces the seashore sign $[17,20]$. The absence of the lung pulse sign further contributes to the diagnosis [21] ( $\bullet$ Fig. 5).

In the recumbent patient, air inside the pleural space moves anteriorly and the partially collapsed lung allocates in the dependent part. The scanning position at the lateral chest with the alternating pattern of pneumothorax into healthy lung is called the "lung point". For documentation, M-mode images may be helpful: The static pattern of the stratosphere sign with parallel horizontal lines (as they result from air inside the pleural space) changes into the granular "seashore sign" once the lung tissue comes into contact with the chest wall as an "on/off" pattern. It has an overall sensitivity of $66 \%$ (75\% in the case of radio-occult pneumothorax alone) and a specificity of $100 \%[3,22]$. In the presence of an air-fluid level (hydro-pneumothorax), the interface between the pleural effusion (usually anechoic) and the pneumothorax component (absence of sliding or pulse and absence of B-lines) is called the "hydro point" [21]. The absence of lung sliding but presence of B-lines and/or lung pulse with the presence of a lung point is diagnostic of septate pneumothorax [21]

In practical application a suggested algorithm for the evaluation for pneumothorax comprises (1) assessment of the sliding lung sign as the first step (if present, pneumothorax can be excluded). Then (2), if lung sliding is absent, further evaluation would look for artifacts (B-lines exclude pneumothorax) and (3) the presence of the lung point sign (this would confirm pneumothorax). At this step in the algorithm, if the sliding lung sign, $\mathrm{B}$-lines and a lung point cannot be observed, the presence of a lung pulse may still rule out pneumothorax while its absence further supports the diagnosis (4) ( $\triangleright$ Fig. 6). An overall sensitivity of this algorithm of $92 \%$ for the diagnosis of pneumothorax has been reported $[6,14]]$. Hence, lung ultrasound is considered more accurate in the diagnosis of pneumothorax than a bedside supine anterior chest $\mathrm{X}$-ray (evidence level $\mathrm{A}$ on international consensus) and may even replace $C T$ in many cases [6, 23]. However, an absence of lung sliding, B-lines, lung point and lung pulse will be similarly observed in conditions such as lung bullae, contusions, pleurodesis or other causes of adhesion of the pleural leaves and may result in false-positive diagnosis [6].

\section{Acute lung disease}

Non-aerated lung tissue due to massive lung edema, lobar bronchopneumonia, pulmonary contusion or atelectasis allows for deep penetration of ultrasound waves. All of these can be detected readily when adjacent or close to the pleural surface or in the presence of pleural effusion.

\section{Consolidation and atelectasis}

Lung US is highly effective in the detection of consolidation and atelectasis and differentiation of these from pleural effusion [14]. The collapsed or consolidated lung appears as poorly defined, wedge-shaped, hypoechoic tissue ( $\bullet$ Fig. $7 a$ ). A preserved volume of the lobe due to fluid uptake in consolidation or a volume loss with dislocation of adjacent structures in atelectasis helps to distinguish between the two conditions. However, a combination of both patterns is common. Consolidated lung tissue appears with a tissue-like pattern reminiscent of the liver ("hepatization") and with a usually irregular deep boundary to the aerated lung in the case of partial lobe involvement or regular in the case of whole lobe involvement [24]. This irregularly shaped margin has also been referred to as the "shred sign" [25] ( $\bullet$ Fig. 7b). Hyperechoic small structures within consolidation correspond to "air bronchograms" ( $\triangleright$ Fig. 7c) [26]. A positive "dynamic air bronchogram" with centrifugal progression of the air bronchogram signal in inspiration is suggestive of alveolar consolidation instead of bronchial occlusion with subsequent lung collapse and atelectasis [25].

On radiograms, airway occlusion can be detected only after resorption of gas and atelectatic collapse of the excluded part of the lung. Lung US already shows an absence of lung sliding with persisting vibrations from the heart activity at the pleural line ("lung pulse sign") while the lung is still inflated (see above, - Fig. 3). Lichtenstein et al. reported a sensitivity of $93 \%$ and a specificity of $100 \%$ for this sign for the diagnosis of complete atelectasis after selective intubation [27]. However, other conditions associated with alterations in lung sliding need to be taken into account (e. g., lung fibrosis, pleural adhesion, diaphragmatic dysfunction and increased abdominal pressure). If a "lung pulse" is already present before intubation, ultrasound cannot predict atelectasis after selective intubation [26, 27]. 


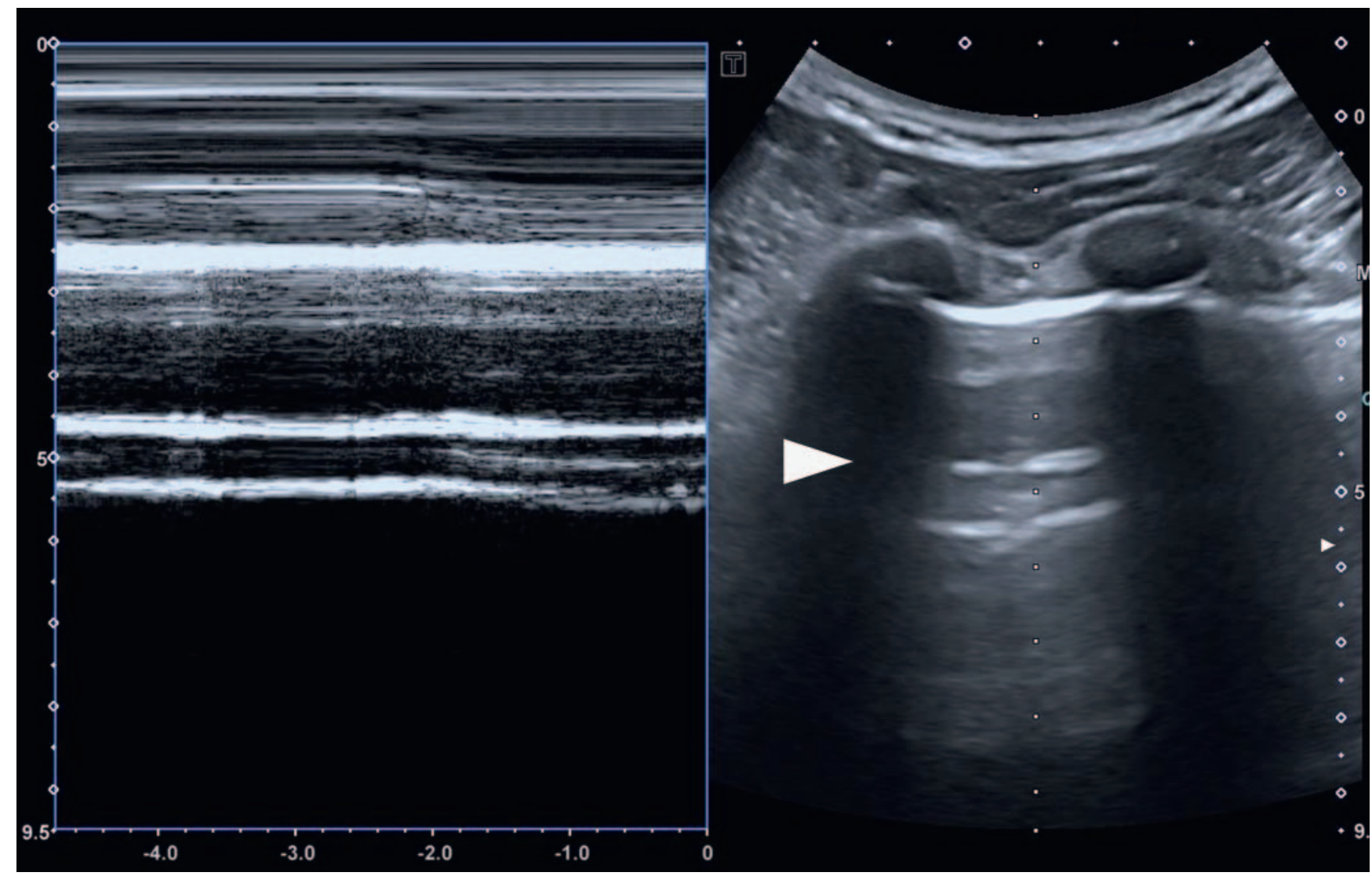

Fig. 5 Pneumothorax: Presence of horizontal reverberation artifacts, but no lung sliding can be observed in B-mode imaging (right). The arrowhead indicates a repeat artifact of the pleural line (so-called "A-line"; per definition corresponding to the distance of the pleural line to the probe). In M-mode (left), the absence of motion is documented as a static pattern of horizontal lines ("stratosphere sign") which replaces the seashore sign. The absence of the lung pulse further contributes to the diagnosis of pneumothorax.

- Abb. 5 Pneumothorax, erkennbar an horizontalen Reverberationsartefakten jenseits der Pleuralinie, aber ohne Pleuragleiten im B-Bild (rechts). Die weiße Pfeilspitze markiert einen Reverberationsartefakt der Pleuralinie (sogenannte A-Line, die per definitionem im doppelten Abstand Schallkopf-Pleuralinie zu beobachten ist). Im M-Bildmodus (links) fehlen die feinkörnigen Reflexe des bewegten Lungengewebes, indessen zeigen sich die statischen horizontalen Linien des Stratosphären-Zeichens („stratosphere sign“). Ein weiterer Hinweis auf das Vorliegen eines Pneumothorax ist das Fehlen des Lungenpulses.

Besides X-ray, ultrasound imaging serves as a fast and easily available bedside test for the assessment of lung aeration during mechanical ventilation [28, 29]. Alternatively, only electrobioimpedancy (EIT) provides real-time monitoring of chest impedance correlating with air content or fluid accumulation, but unlike $X$-ray and ultrasound, ventilation maps of the lung generated with EIT do not contribute information about the morphology of the affected tissue [30].

\section{B-lines/B-pattern}

The further investigation of diffuse or focal parenchymal disease is based on hyperechoic vertical artifacts, summarized as "B-lines" or "B-pattern" [31]. They arise from the pleural line and indicate thickening of interlobular septa due to congestive or fibrotic changes. These hyperechoic artifacts are long, relatively sharply delineated and obliterate horizontal reverberations from the pleural line ( $>$ Fig. 8). Due to their origin from the pleural line, B-lines follow lung sliding during respiration. Instead of more descriptive terms, such as comet tail or rocket sign (for single and multiple B-lines), it is recommended to use the generic term "B-pattern" [6]. Per definition, the appearance of B-lines rules out pneumothorax since they could not be generated through an air filling of the pleural space [32].

Notably, single B-lines are not necessarily a sign of critical illness, since they may be found in healthy, elderly subjects (in one study they were present in 37 of 100 persons aged more than 65 years, with $27 / 37$ having 3 or less lines per field of view). Horizontal reverberations from the pleural line (formerly called "A-lines") instead become rare with age (present in only 6/100) [33]. In the newborn, a decrease of B-lines on ultrasound and an increase of lung compliance during the first $24 \mathrm{~h}$ after birth reflect the clearance of lung liquid [34].

Septal B-lines indicate edematous or fibrous thickening of interlobular septa. They typically appear at a distance of 6 or $7 \mathrm{~mm}$ apart according to the anatomic distance between two interlobular septa ( $\triangleright$ Fig. 8). Sets of at least three hyperechoic B-lines arising from the pleural line in one intercostal space are indicative of interstitial lung syndrome. In dyspneic patients, they are indica- 
tive of diffuse alveolar-interstitial involvement and allow for fast bedside diagnosis of pulmonary congestion or interstitial pneumonia [35-37]. With this, lung ultrasound for B-lines is superior to supine anterior chest $\mathrm{X}$-ray in the detection or the exclusion of

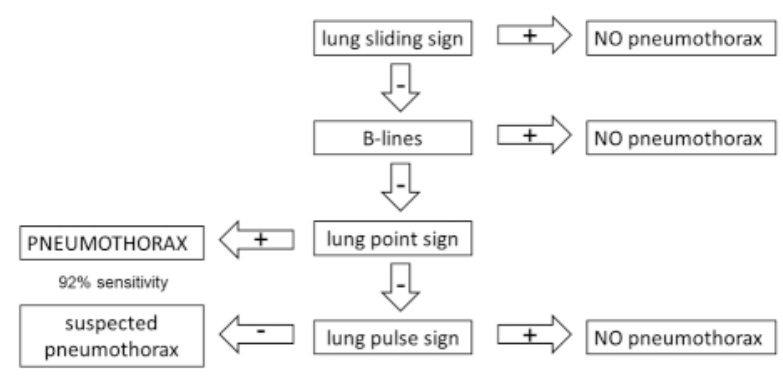

- Fig. 6 Algorithm for the detection of pneumothorax with lung US (adapted from [6]). caveat: Only the documentation of the lung point sign allows for the sonographic diagnosis of pneumothorax. An absence of lung sliding, B-lines, lung point and lung pulse may be also observed in other conditions such as lung bullae, contusions, pleurodesis or other causes of adhesion of the pleural leaves leading to a false-positive diagnosis of pneumothorax. Therefore, the absence of the above-mentioned signs only allows for the diagnosis of "suspected pneumothorax".

- Abb.6 Algorithmus zur Diagnostik des Pneumothorax mittels Ultraschall (modifiziert nach [6]). Cave: Nur die Dokumentation des „lung point“-Zeichens sichert die Diagnose ab. Das Fehlen des Pleuragleitens, fehlende B-Linien und fehlender Lungenpuls ohne Nachweis eines „lung point“ können auch in anderen Situationen wie Bullae, Lungenkontusion, Zustand nach Pleurodese oder in anderen Fällen pleuraer Adhäsionen vorliegen. In diesen Fällen sollte nur der Verdacht auf einen Pneumothorax geäußert werden. significant interstitial syndrome (evidence level B) [6]. In acute dyspnea, the presence of $\mathrm{B}$-lines is a useful discriminator between pulmonary edema (B-lines present in $100 \%$ ) and a respiratory cause, e. g. exacerbation of COPD (B-lines absent in $92 \%$ ) [38, 39].

As B-lines may be influenced by multiple factors, ongoing investigation is done to further determine the role of different transducers and the clinical significance of findings on higher resolution ultrasound imaging [31]. Li et al., for example, investigated the diagnostic value of pleural line changes in conjunction with $\mathrm{B}$-lines. The coexistence of $\mathrm{B}$-lines with more than one abnormal pleural line was found in about $30 \%$ of cases: 1 ) a slightly rough pleural line with confluent B-lines corresponded to ground-glass opacity on $\mathrm{CT} ; 2$ ) an irregular and interrupted pleural line with confluent B-lines - parenchymal infiltration; 3) a fringed pleural line and confluent B-lines - superimposed groundglass and irregular reticular opacities; 4) a fringed pleural line with scattered B-lines - irregularly thickened interlobular septa; 5) a wavy pleural line indicated subpleural emphysema [40].

Differential diagnosis with respect to other vertical (formerly called "comet tail") artifacts is based on the origin. "E-lines" originate from emphysema in the chest wall and thus do not follow lung sliding. "Z-lines" appear as vertical hyperechoic artifacts arising from the pleural line, but do not reach the distal edge of the screen, typically found in healthy persons and patients with pneumothorax [17]. "T-lines", as they result from the lung pulse sign, have already been mentioned above.

\section{Interstitial lung edema}

In practical application, a fast anterior two-region scan allows confirmation or ruling out of acute lung edema with high diagnostic accuracy [7]. Notably, the change from A- to B-pattern in lung congestion appears at a threshold of $18 \mathrm{mmHg}$ of pulmonary ar-

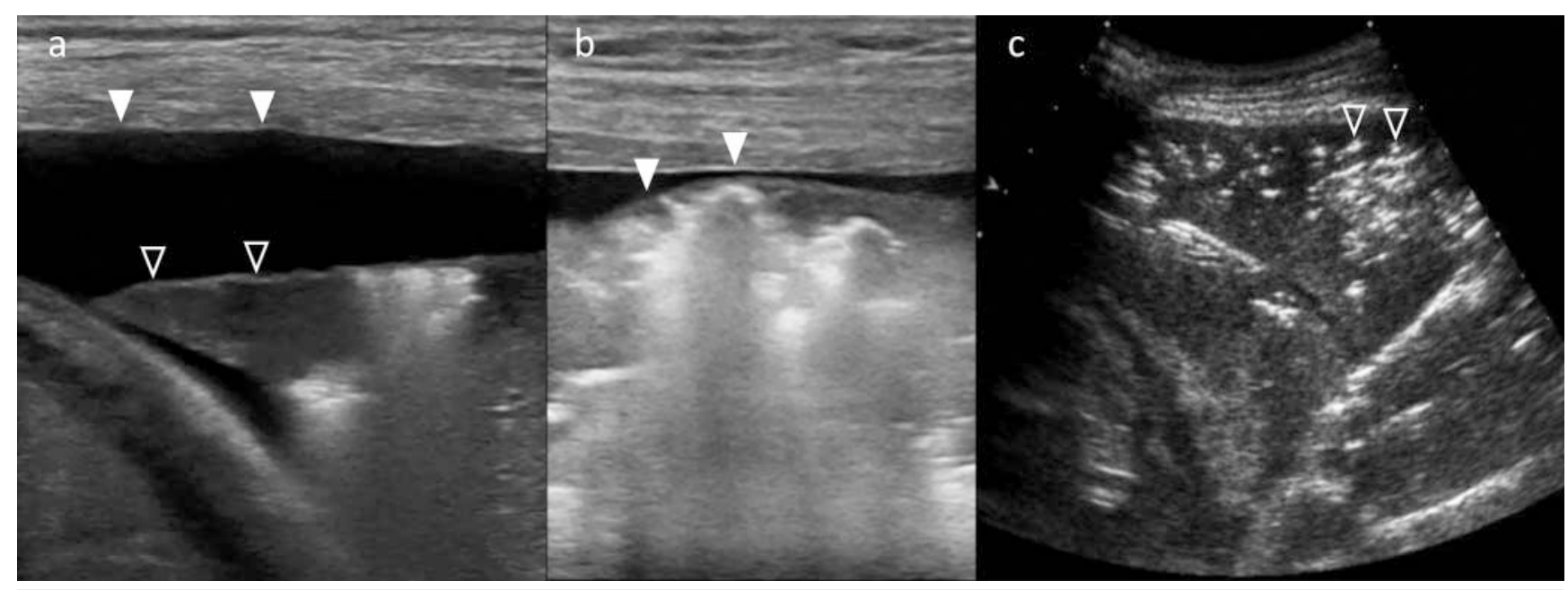

- Fig. 7 a Pleural effusion (arrowheads) and atelectasis of the laterobasal lower lobe (open arrowheads). Hyperechoic artifacts delineate the transition from atelectatic to ventilated lung. b Pneumonia and sub-pleural atelectasis with irregular boundary to the aerated lung ("shred sign", arrowheads). c Air bronchogram inside atelectatic lung (open arrowheads).

- Abb. 7 a Pleuraerguss (weiße Pfeilspitzen) und Atelektase des laterobasalen Unterlappens (transparente Pfeilspitzen). Hyperechogene Artefakte demarkieren den Übergang vom atelektatischen zum belüfteten Lungengewebe. b Pneumonie und subpleurale Atelektasen mit unregelmäßiger Begrenzung zur belüfteten Lunge („shred sign“, weiße Pfeilspitzen). c Aerobronchiogramm innerhalb der atelektatischen Lunge (transparente Pfeilspitzen). 


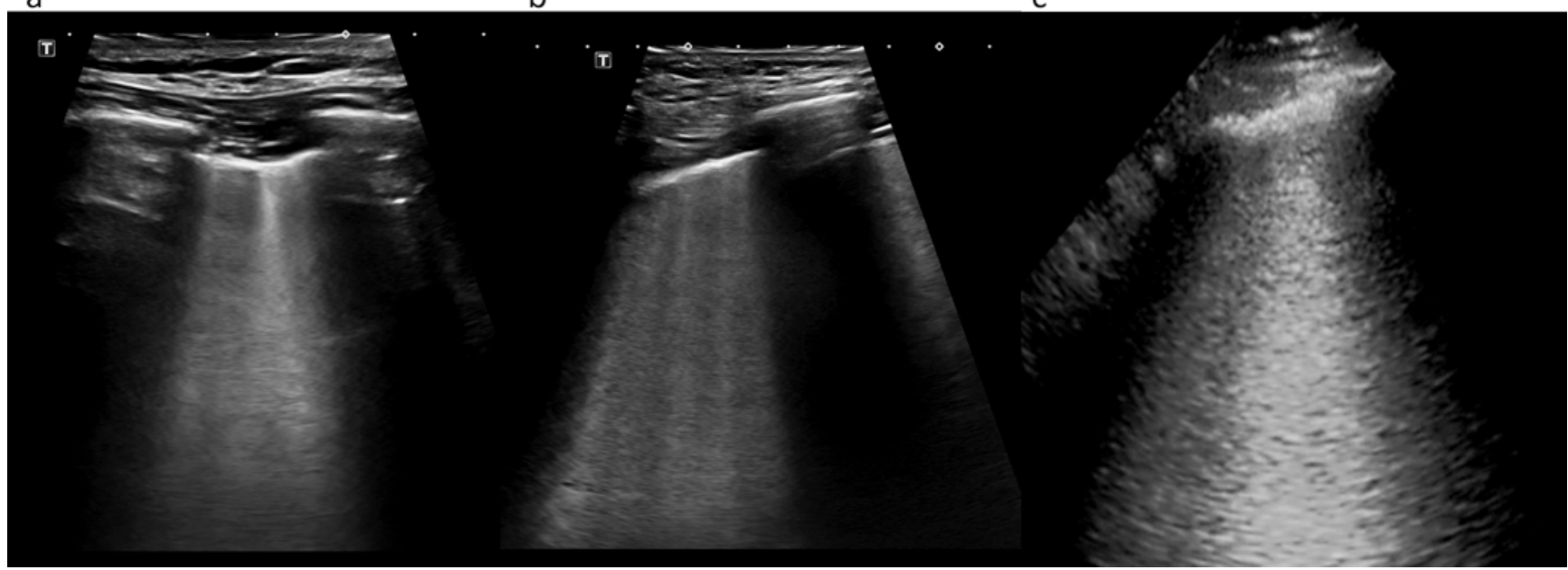

- Fig. 8 Single a and multiple b B-lines (vertical bright lines) in ICU patient with lung interstitial edema. c confluent B-lines ("white lung") in a patient with ARDS.

- Abb. 8 Einzelne a und multiple b B-Linien (helle, vertikale Linien) bei einem intensivmedizinisch versorgten Patienten mit interstitiellem Lungenödem. c konfluente B-Linien („weiße Lunge“) bei einem Patienten mit ARDS.

tery occlusion pressure and serves as a direct biomarker of clinical volemia [17]. In interstitial edema, the number of B-lines correlates with fluid accumulation and the extent of parenchymal changes on CT [41]. When originating from accumulation of intra-alveolar fluid (ground glass opacities on X-ray or CT), they appear in an even higher number and are allocated closer to each other compared to septal B-lines ( $3 \mathrm{~mm}$ or less apart correlating with the degree of reduced aeration). For a semi-quantitative assessment of the severity of pulmonary congestion, it has been suggested to count the number of B-lines in multiple intercostal spaces (28-site scanning technique) or the number of positive scans (eight-region technique) [6, 14].

This knowledge can be used for fluid administration management in shock patients (fluid administration limited by lung sonography = FALLS protocol). After exclusion of pericardial effusion/ tamponade, acute pulmonary embolism (enlargement of the right ventricle), pneumothorax (A-pattern) and pulmonary congestion (B-pattern) with lung US, fluid administration is started until the appearance of B-lines indicates subclinical iatrogenic interstitial edema [17]. A lack of clinical improvement following this fluid administration is considered diagnostic for distributive septic shock [17].

\section{Lung disease with inhomogeneous distribution}

The differential diagnoses for an interstitial syndrome pattern on lung ultrasound include pulmonary edema of various causes including ARDS, interstitial pneumonia or pneumonitis or diffuse parenchymal lung disease (lung fibrosis). A focal (localized) sonographic B-pattern of interstitial syndrome is also found in some cases of atelectasis, pulmonary contusion, pulmonary infarction and neoplasia. The differentiation is based on the distinction of focal and diffuse sonographic pattern and other sonographic signs [6].

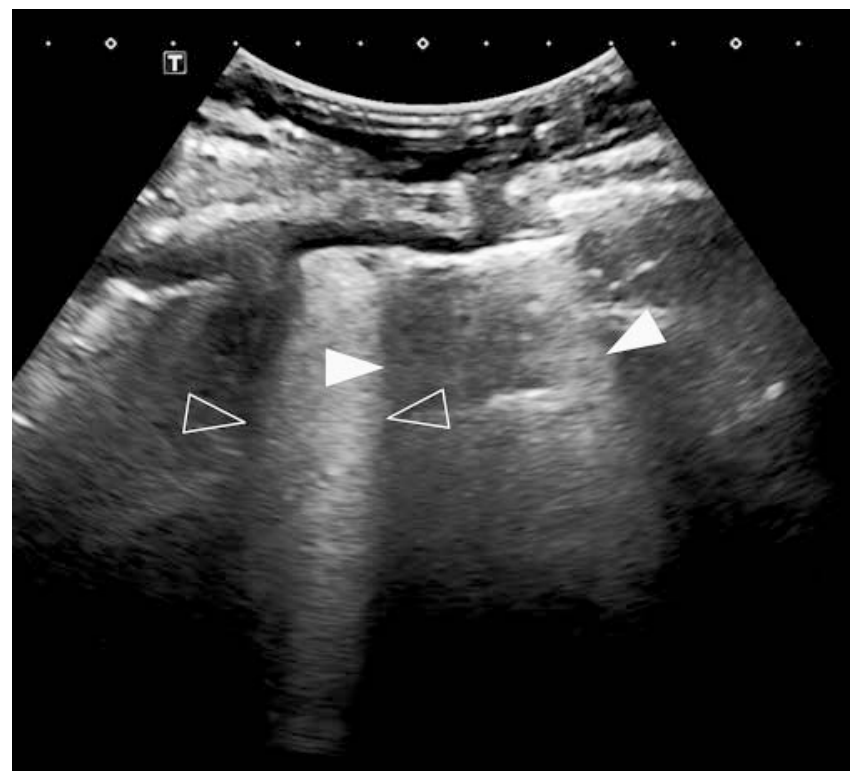

- Fig. 9 "Spared areas" of intact lung (arrowheads) adjacent to "white lung" (open arrowheads) in a patient with ARDS.

- Abb. 9 Verschonte Areale intakter Lunge („spared areas“, weiße Pfeilspitzen) neben „weißer Lunge“ (transparente Pfeilspitzen) bei einem Patienten mit ARDS.

\section{ARDS}

Non-cardiogenic pulmonary edema related to ARDS is distinguished from cardiogenic edema by the more inhomogeneous distribution of B-lines and inhomogeneous involvement of lung parenchyma with "spared areas" of normal parenchyma ( $\vee$ Fig. 9). Together with the absence or reduction of lung sliding and the presence of pleural line abnormalities (irregularly thickened and fragmented appearance of the pleural line), ARDS can 
be clearly differentiated (evidence level B) [6, 42]. Further signs suggesting the presence of ARDS are consolidations, pleural effusion and a lung pulse sign [42]. Similarly, respiratory distress syndrome in neonates presents with bilateral, confluent B-lines, absence of spared areas and pleural line abnormalities, making it a highly sensitive test for this condition in the pediatric setting and obviating the need for chest X-ray $[6,43]$. In suspected transient tachypnea of the newborn (TTN), the diagnosis is established by the finding of bilateral confluent B-lines in the dependent areas of the lung ("white lung"') with a normal or nearnormal appearance of the lung in the superior fields (see above, - Fig. 8c) [6, 44]. In pregnant women lung US can serve to observe pulmonary edema in preeclampsia, to avoid intravenous or excess fluids, which can lead to respiratory failure [45].

\section{Pneumonia}

Reissig et al. conducted a prospective, multicenter study on the accuracy of lung ultrasound in the diagnosis and follow-up of community-acquired pneumonia [9] ( $\$$ Fig. 10). In 362 patients in 14 centers, lung ultrasound had a sensitivity of $93.4 \%$ and a specificity of $97.7 \%$ for pneumonia compared to the reference of final clinical diagnosis. Breath-dependent motion of infiltrates was seen in $97.6 \%$ of the cases, an air bronchogram in $86.7 \%$, blurred margins in $76.5 \%$ and a basal pleural effusion in $54.4 \%$ [9]. Bourcier et al. have discussed that lung US might even replace routine chest radiography in the first-line diagnosis of acute communityacquired pneumonia and to reserve chest CT scan for complicated cases [15]. On the other hand, $8 \%$ of the pneumonic lesions were missed in the study of Reissig et al. Therefore, they concluded that a normal lung ultrasound examination does not reliably exclude pneumonia [9]. These numbers appear in a different light when compared to chest radiograms in recumbent patients, which are frequently of poor quality and difficult to interpret. With lung US, the examining physician can adjust to the individual situation and repeat scanning without having to be concerned about radiation exposure. Only recently, Alzahrani et al. have provided a systematic review and meta-analysis on the diagnostic accuracy of ultrasound for the diagnosis of pneumonia versus radiological imaging with X-ray and CT (including 20 studies with an total of 2513 subjects). The pooled sensitivity and specificity for the diagnosis of pneumonia by lung ultrasound were $0.85(0.84-0.87)$ and 0.93 $(0.92-0.95)$, respectively. The overall pooled positive and negative LRs were $11.05(3.76-32.50)$ and $0.08(0.04-0.15)$ and the area under the pooled ROC (AUC for SROC) was 0.978 [46].

In pregnant patients, community-acquired pneumonia is the most common fatal non-obstetric infectious complication and a common cause of hospitalization [47]. Diagnosing pneumonia in pregnancy by lung US can affect pregnant women by determining health risks for the mother and fetus, while avoiding unnecessary $\mathrm{X}$-ray exposure. However, further studies are required to validate the shift of imaging modality on a larger scale [48] ( $\triangleright$ Fig. 11).

Similar ultrasound signs of pleural diseases and pneumonia are found in pediatric patients. For the diagnosis of pneumonia in children, lung ultrasound is considered as accurate as chest radiography (international consensus, evidence level A) [6, 49]. According to this guideline, a positive lung ultrasound in children with suspected pneumonia obviates the need for additional radiography. In contrast to adult patients, intravenously injected ultrasound contrast media (e.g. SonoVue, Bracco, Milan) already play a role in imaging and intervention in complex pneumonia in children. They have been applied successfully to distinguish between necrotic and vital lung in necrotizing pneumonia when grayscale US was not conclusive. Atelectasis can be readily differentiated from empyema by the vascular enhancement ( $\triangleright$ Fig. 12 ). For interventions, this may be helpful to establish the indication for catheter placement and selection of the proper position for drains [50]. Intracavitary contrast material application can help to establish the indication for drainage, detection of septa hindering the complete drainage of the pleural effusion (e.g. in multi-septated effusion suggesting the use of Streptokinase) and to finally choose the appropriate timing for catheter removal [44].

\section{Chronic lung disease}

\section{Pulmonary fibrosis}

Given the high sensitivity of lung ultrasound regarding changes in the peripheral lung, its capacity to detect interstitial lung disease related to pulmonary fibrosis is not surprising [51]. Interstitial fibrosis with thickened interlobular and intralobular septa results in an inhomogeneous, diffuse B-line pattern. The combination with pleural abnormalities and sub-pleural abnormalities that correlate with the typical findings on $\mathrm{CT}$ in these conditions helps to differentiate from cardiogenic pulmonary edema [6, 52]. In patients with systemic sclerosis, a high sensitivity of lung ultrasound for early findings of lung and pleura involvement before the onset of clinical symptoms has been shown and it has been suggested to use it as a routine test to identify patients for selective referral to HRCT $[53,54]$. A comprehensive assessment, e. g. for scientific use, includes evaluation at 50 positions in intercostal spaces, but for practical application, an abbreviated protocol would include 14 positions (the second intercostal space parasternal, the fourth along the mid-clavicular, anterior axillary and mid-axillary lines, and the eighth along the paravertebral, sub-scapular and posterior axillary lines) and can be performed in less than 10 minutes [55]. Instead of this time-consuming manual assessment of $\mathrm{B}$-line frequency, software-based analysis has been suggested to classify the degree of pulmonary edema and pulmonary fibrosis with high feasibility and over different levels of severity $[52,56]$.

\section{Obstructive lung diseases}

Generally, the hyperinflation of lung tissue due to emphysema increases the artifacts and makes lung ultrasound even more difficult. Consequently, nonspecific signs of air dominance beneath the pleura such as horizontal reverberations from the pleural line (formerly called "A-lines") and other lines parallel to these are the predominant pattern [17]. Functional impairment of respiratory mechanics can be estimated from diaphragm muscle thickness and diaphragmatic motion. Patients with high risk prior to general anesthesia, mechanical ventilation, or invasive procedures can be identified [57]. While the observation of diaphragmatic motion with $\mathrm{B}$-mode imaging is the key to diagnosis, M-mode recordings can be used to document the displacement. In analogy to the 


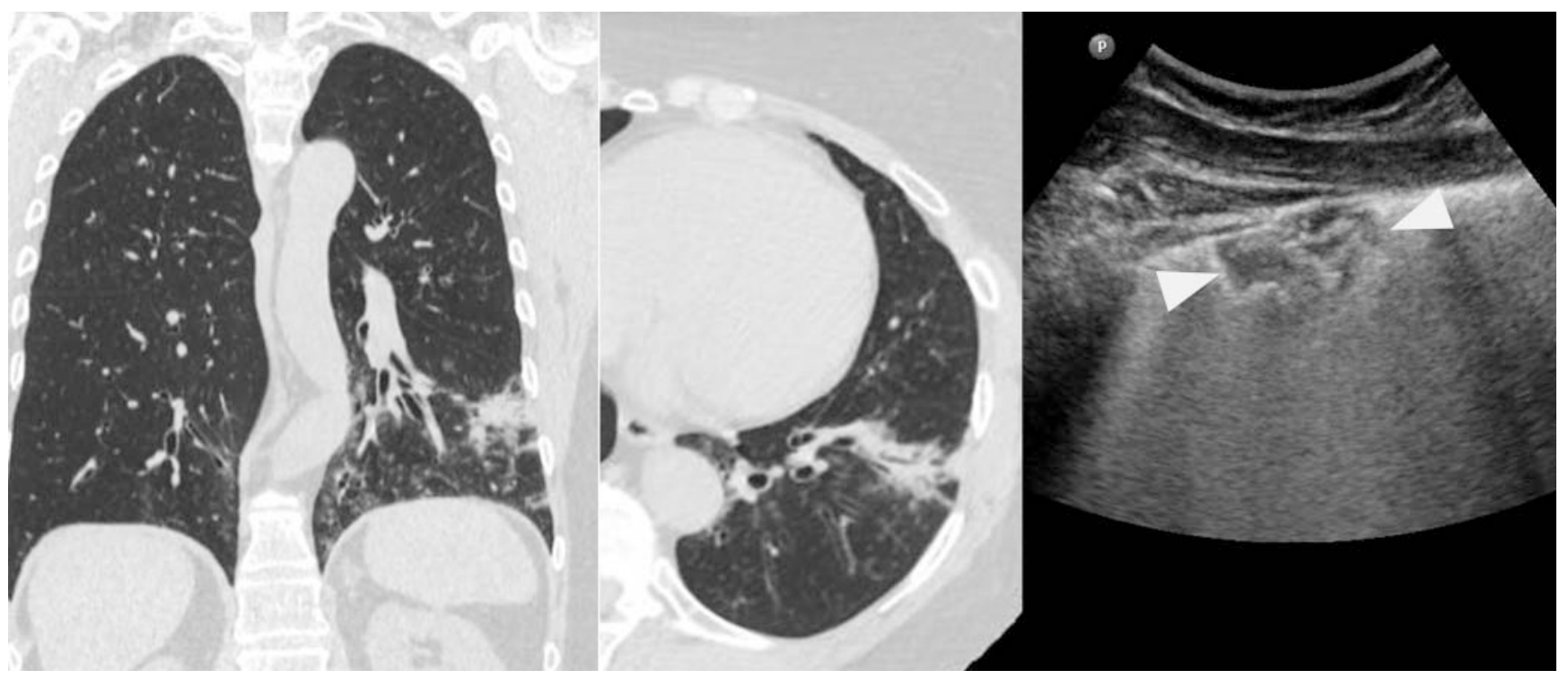

- Fig. 10 Lateral left lower lobe subpleural pneumonia in a 61-year-old female (M. pneumoniae); left: MSCT coronal reformation; middle: transverse CT slice; right: ultrasound shows hypoechoic irregular lung infiltration (arrowheads) through the left lateral 8th intercostal space.

- Abb. 10 Links laterobasales subpleurales pneumonisches Infiltrat, 61 Jahre alte Patientin (M. pneumoniae); links: koronare CT-Rekonstruktion; Mitte: transversale CT-Schicht; rechts: Die Sonographie in Höhe des 8. links lateralen Zwischenwirbelraumes zeigt eine hypoechogene, unregelmäßige Infiltration der Lunge (Pfeilspitzen).

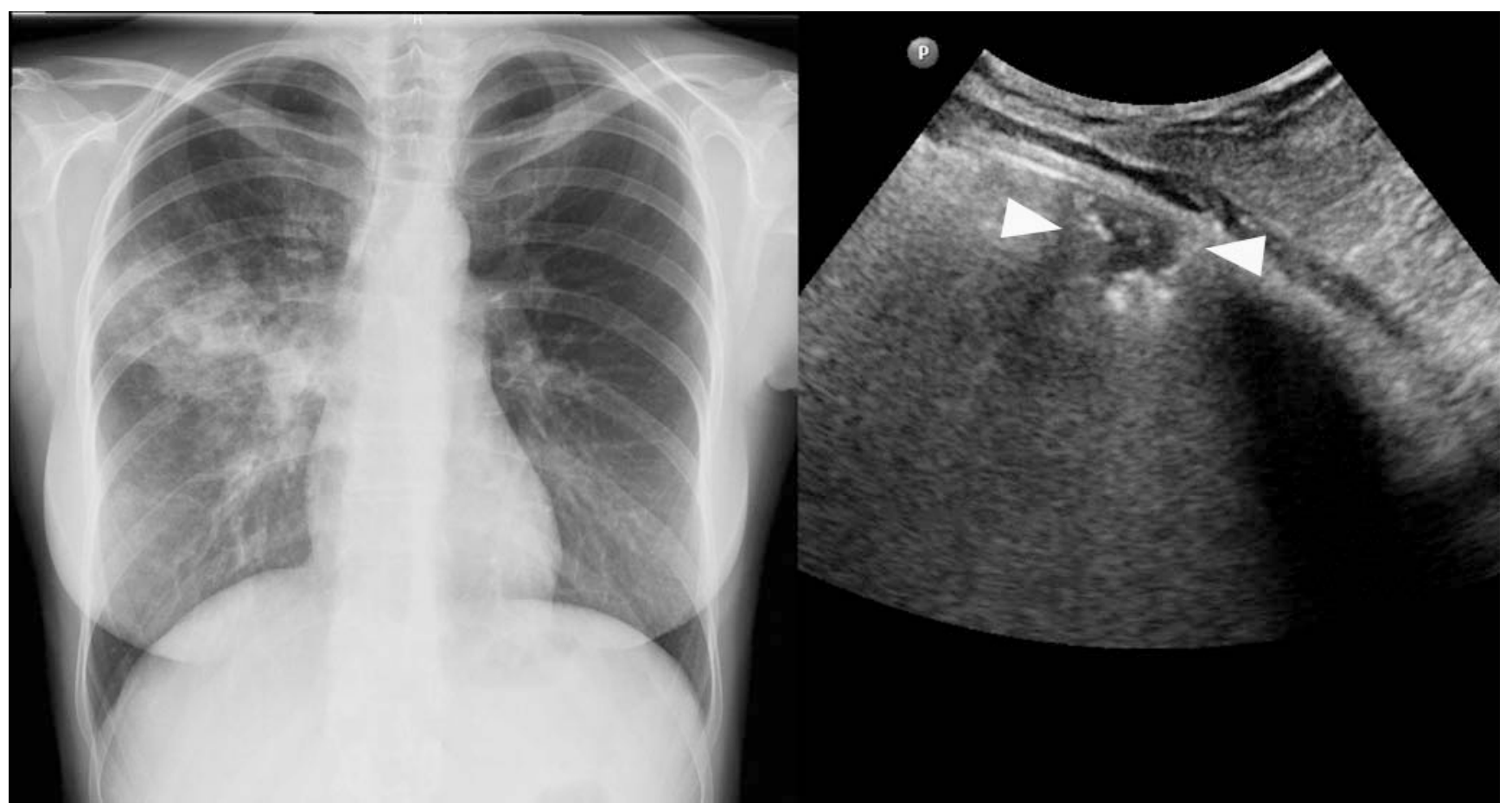

- Fig. 11 Anterior right upper lobe pneumonia in a 33-year-old pregnant woman (left: PA chest X-ray, right: Lung ultrasound through the right anterolateral $3 \mathrm{rd}$ intercostal space). The ultrasound examination shows only a small lesion (arrowheads) due to limited ultrasound penetration through well aerated tissue surrounding the consolidation.

- Abb. 11 Pneumonisches Infiltrat im anterioren rechten Oberlappen einer 33 Jahre alten, schwangeren Patientin (links: Röntgenübersicht p.-a., rechts: Ultraschall durch den dritten rechts anterolateralen Interkostalraum). Die Sonographie zeigt nur eine kleine pleuraständige Läsion (Pfeilspitzen), da interponiertes, belüftetes Lungengewebe die tiefer gelegenen Anteile des Infiltrates maskiert. 


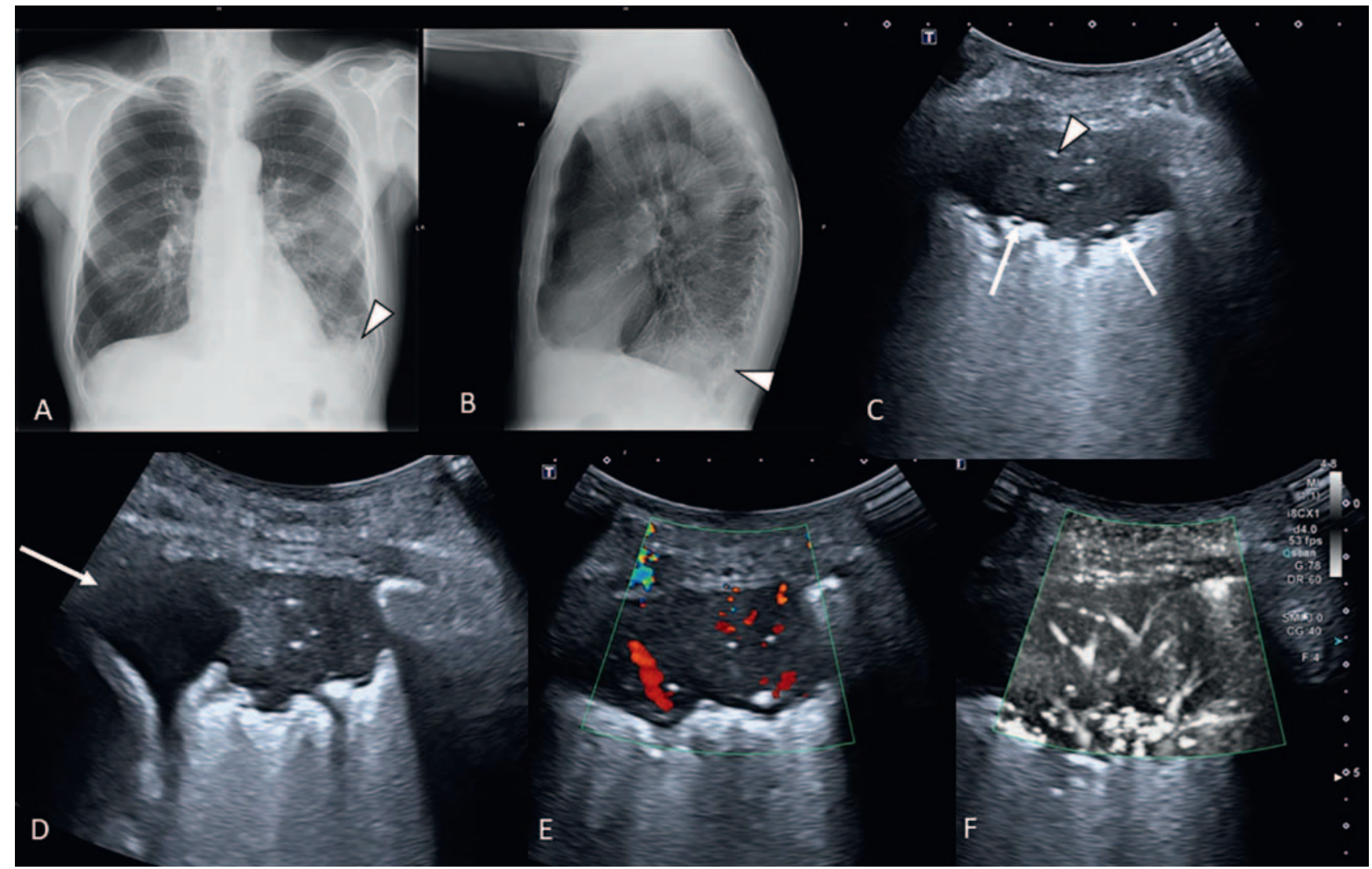

- Fig. 12 Pleuropneumonia. 68-year-old male patient, symptomatic 4 days with febrile temperature, productive cough, left lower chest pain, elevated inflammatory markers in laboratory tests (CRP>200 mg/L). On X-ray left lower lobe posterior segmental pneumonia (B - arrowhead) and obscured costodiafragmal sinus due to effusion (A - arrowhead). The lung ultrasound shows local consolidation with few air bronchograms (bright spots on the dark grey background), (C-arrows - infiltration, arrowhead - air bronchogramms) on the left lower lung lateral surface with adjacent black pleural effusion ( $\mathbf{D}$ - arrow) and marked hypervascularization in the lesion (E - color in color Doppler mode, $\mathbf{F}$ - microvascularization mode), suggestive of pleuro-pneumonia.

- Abb. 12 Pleuropneumonie: 68 Jahre alter Patient, seit 4 Tagen symptomatisch mit Fieber, produktivem Husten, links basalem Thoraxschmerz und erhöhten Entzündungswerten (CRP> $200 \mathrm{mg} / \mathrm{l}$ ). Die Röntgenübersicht zeigt ein segmentales Infiltrat des posterioren linken Unterlappens (B - Pfeilspitze) und einen Randwinkelerguss (A - Pfeilspitze). Der Lungen-Ultraschall zeigt links laterobasal lokale Konsolidationen mit einigen wenigen Aerobronchogrammen (C - weiße Flecken vor dem dunklen Hintergrund des atelektatischen Lungengewebes; Pfeile - Infiltration, Pfeilspitze - Aerobronchiogramm), angrenzend Pleuraerguss (D - Pfeil). Markante Hypervaskularisation des Befundes (E - Farbdopplermodus, F - Powerdoppler-Modus).

time/volume curve of spirometry, the calculated M-mode Index of Obstruction (MIO) from the ratio between forced diaphragmatic excursion in the first second and the maximal expiratory diaphragmatic excursion correlates linearly with airway obstruction [58]. In the general clinical setting, the detection of abnormalities in respiratory motion can contribute to the early detection of COPD as an ancillary finding in abdominal ultrasound [59].

\section{Pulmonary malignancy}

Pulmonary involvement is common in various oncologic diseases. While endobronchial or esophageal ultrasound have become an important modality for the evaluation of mediastinal lymph node metastases [60], peripherally located focal primary tumor (rarely) or secondary metastatic lesions (frequently) may still be depicted on transthoracic ultrasound if they are located subpleural or invade thoracic wall structures [61]. The hallmark of these lesions includes the hypoechoic lesion or multiple lesions intrapulmonary adjacent to the pleural space or thoracic wall, with marked blood supply shown on color Doppler, microvascular imaging and contrast-enhanced ultrasound (fast hemodynamics of contrast media with wash-in and fast wash-out), which helps with respect to differential diagnosis from pulmonary embolism (avascular lesion) [62]. However, a differentiation of malignancy and focal lesions in pneumonia may be difficult [63]. Therefore, these features are appreciated for planning and performing US-guided biopsy, i. e. to detect the best vascularized portion and to obtain representative, viable tissue samples [64].

\section{Pulmonary vascular disease}

The clinical workhorse in the diagnosis of acute pulmonary embolism (PE) is computed tomography angiography (CTA). However, a fast and reasonably sensitive bedside test for this acute, life- 
threatening condition would be desirable on many occasions. Lung ultrasound is blind to central pulmonary embolism, but obviously a substantial number of pulmonary emboli involve the peripheral lung. The ultrasonography hallmark of acute PE in the periphery is triangular, hypoechoic, and pleural-based parenchymal lesions due to peripheral pulmonary infarction with localized and/or basal effusion (from radiography also known as Hampton's hump) [65] and abrupted vessel on color Doppler imaging corresponding to a hypovascular area [66]. In a prospective multicenter trial based on these signs, Mathis et al. demonstrated a sensitivity of $74 \%$ and a specificity of $95 \%$ for lung ultrasound for the diagnosis of peripheral pulmonary embolism (352 patients with a PE prevalence of $55 \%$ confirmed by CTPA, positive predictive value $95 \%$, negative predictive value of $75 \%$, accuracy of $84 \%$ ) [66]. The diagnostic confidence was highest in the presence of two or more typical triangular or rounded pleural-based lesions. PE was considered probable if there was one typical lesion in combination with pleural effusion. Small $(<5 \mathrm{~mm})$ subpleural lesions or a single pleural effusion alone was considered a sign for possible PE. On international consensus level lung ultrasound has been acknowledged as an alternative diagnostic tool for the diagnosis of PE when CT is contraindicated or unavailable (evidence level A) [6]. Ongoing research is focused on contrastenhanced ultrasound with intravascular contrast agents for the diagnosis of perfusion deficits in acute pulmonary embolism, but its role in the routine is not yet defined [67].

\section{The full picture: Comprehensive assessment of pulmonary disease}

The fast and efficient application of the above-described knowledge for the diagnosis of acute respiratory failure defines the need for a structured approach. For this purpose, Lichtenstein et al. have advocated the "bedside lung ultrasound in emergency (BLUE) protocol" [7]. It covers important pathologies such as pneumonia, congestive heart failure, COPD, asthma, pulmonary embolism and pneumothorax. It can be performed in less than 3 minutes within the first 20 minutes of admission and would be completed with echocardiography [17]. The first step in the algorithm is the detection of lung sliding, then the predominant artifact pattern is assessed. Lung sliding with predominantly horizontal reverberations ("A-pattern") is suggestive for asthma or COPD. Lung sliding with bilateral appearance of an anterior B-pattern indicates pulmonary edema. Lung sliding with a normal anterior appearance of the lung plus deep venous thrombosis is suggestive for pulmonary embolism. Absent lung sliding with horizontal reverberation artifacts ("A-pattern") and with a lung point sign is found in pneumothorax. Independently on lung sliding, anterior alveolar consolidations, anterior diffuse B-lines, anterior asymmetric interstitial patterns, posterior consolidations or effusions are found in different types of pneumonia. The sensitivity and specificity of these findings range from $80-100 \%$. Overall a correct diagnosis was established in $90.5 \%$ of cases [7, 17].

\section{Conclusion}

Diagnostic scope, increasing clinical experience and the widespread availability of high quality equipment encourage more frequent use of lung ultrasound for the assessment of pleural and cardiopulmonary diseases. Lung ultrasound may be advised as the first-line imaging method in the acute setting, as it is well acknowledged in the fast emergency room assessment of acute respiratory failure and as a bedside test for interstitial lung edema. It may also serve as a complimentary modality to other imaging methods or in the follow-up of known conditions, such as the diagnosis of pneumonia, atelectasis or for the assessment of pleural effusion and pleurisy with high accuracy. It is a useful ancillary technique for thoracic interventions in acute, complicated or oncologic diseases. Last but not least, the increasing concerns about medical radiation exposure may also encourage general radiologists to use this sometimes underestimated modality more frequently.

\section{Conflict of Interest}

The authors declare that they have no conflict of interest.

\section{References}

[1] Mohanty K, Blackwell J, Egan T et al. Characterization of the Lung Parenchyma Using Ultrasound Multiple Scattering. Ultrasound Med Biol 2017; 43: $993-1003$

[2] Nelson M, Stankard B, Greco J et al. Point of Care Ultrasound Diagnosis of Empyema. J Emerg Med 2016; 51: 140-143

[3] Moreno-Aguilar G, Lichtenstein D. Lung ultrasound in the critically ill (LUCl) and the lung point: a sign specific to pneumothorax which cannot be mimicked. Crit Care Lond Engl 2015; 19: 311

[4] Soldati G, Testa A, Sher S et al. Occult traumatic pneumothorax: diagnostic accuracy of lung ultrasonography in the emergency department. Chest 2008; 133: 204-211

[5] 012-019k_S3_Polytrauma_Schwerverletzten-Behandlung_2016-10.pdf. o. J.

[6] Volpicelli G, Elbarbary M, Blaivas M et al. International evidence-based recommendations for point-of-care lung ultrasound. Intensive Care Med 2012; 38: $577-591$

[7] Lichtenstein DA, Mezière GA. Relevance of lung ultrasound in the diagnosis of acute respiratory failure: the BLUE protocol. Chest 2008; 134 : $117-125$

[8] Mittal AK, Gupta N. Intraoperative lung ultrasound: A clinicodynamic perspective. J Anaesthesiol Clin Pharmacol 2016; 32: 288-297

[9] Reissig A, Copetti R, Mathis G et al. Lung ultrasound in the diagnosis and follow-up of community-acquired pneumonia: a prospective, multicenter, diagnostic accuracy study. Chest 2012; 142: 965 - 972

[10] Lichtenstein D. Novel approaches to ultrasonography of the lung and pleural space: where are we now? Breathe Sheff Engl 2017; 13: 100 111

[11] Soldati G, Smargiassi A, Mariani AA et al. Novel aspects in diagnostic approach to respiratory patients: is it the time for a new semiotics? Multidiscip Respir Med 2017; 12: 15

[12] Gargani L, Volpicelli G. How I do it: Lung ultrasound. Cardiovasc Ultrasound 2014; 12: 25 
[13] Bourcier JE, Braga S, Garnier D. Lung Ultrasound Will Soon Replace Chest Radiography in the Diagnosis of Acute Community-Acquired Pneumonia. Curr Infect Dis Rep 2016; 18: 43

[14] Doerschug KC, Schmidt GA. Intensive care ultrasound: III. Lung and pleural ultrasound for the intensivist. Ann Am Thorac Soc 2013; 10: $708-712$

[15] Jambrik Z, Monti S, Coppola V et al. Usefulness of ultrasound lung comets as a nonradiologic sign of extravascular lung water. Am J Cardiol 2004; 93: $1265-1270$

[16] Umbrello M, Formenti P, Longhi D et al. Diaphragm ultrasound as indicator of respiratory effort in critically ill patients undergoing assisted mechanical ventilation: a pilot clinical study. Crit Care 2015; 19: 161

[17] Lichtenstein DA. BLUE-protocol and FALLS-protocol: two applications of lung ultrasound in the critically ill. Chest 2015; 147: 1659-1670

[18] Lichtenstein DA, Menu Y. A bedside ultrasound sign ruling out pneumothorax in the critically ill. Lung sliding. Chest 1995; 108: 1345-1348

[19] Na MJ. Diagnostic tools of pleural effusion. Tuberc Respir Dis 2014; 76 : $199-210$

[20] Lichtenstein DA. Lung ultrasound in the critically ill. Ann Intensive Care 2014; 4: 1

[21] Volpicelli G, Boero E, Stefanone $V$ et al. Unusual new signs of pneumothorax at lung ultrasound. Crit Ultrasound J 2013; 5: 10

[22] Lichtenstein D, Mezière G, Biderman P et al. The "lung point": an ultrasound sign specific to pneumothorax. Intensive Care Med 2000; 26: $1434-1440$

[23] Lichtenstein DA, Mezière G, Lascols N et al. Ultrasound diagnosis of occult pneumothorax. Crit Care Med 2005; 33: 1231-1238

[24] Lichtenstein DA, Lascols N, Mezière G et al. Ultrasound diagnosis of alveolar consolidation in the critically ill. Intensive Care Med 2004; 30: $276-281$

[25] Lichtenstein D, Mezière G, Seitz ]. The dynamic air bronchogram. A lung ultrasound sign of alveolar consolidation ruling out atelectasis. Chest 2009; 135: 1421 - 1425

[26] Karabinis A, Saranteas T, Karakitsos D et al. The“cardiac-lung mass" artifact: an echocardiographic sign of lung atelectasis and/or pleural effusion. Crit Care 2008; 12: R122

[27] Lichtenstein DA, Lascols N, Prin S et al. The "lung pulse": an early ultrasound sign of complete atelectasis. Intensive Care Med 2003; 29: 2187 2192

[28] Soldati G, Smargiassi A, Mariani AA et al. Novel aspects in diagnostic approach to respiratory patients: is it the time for a new semiotics? Multidiscip Respir Med 2017; 12: 15

[29] Pesenti A, Musch G, Lichtenstein D et al. Imaging in acute respiratory distress syndrome. Intensive Care Med 2016; 42: 686-698

[30] Wierzejski W, Adamski J, Weigl W et al. Modern methods of assessment of lung aeration during mechanical ventilation. Anaesthesiol Intensive Ther 2012; 44: 226-231

[31] Dietrich CF, Mathis G, Blaivas M et al. Lung B-line artefacts and their use. J Thorac Dis 2016; 8: 1356-1365

[32] Lichtenstein D, Mezière G, Biderman P et al. The comet-tail artifact: an ultrasound sign ruling out pneumothorax. Intensive Care Med 1999; 25 : $383-388$

[33] Chiesa AM, Ciccarese F, Gardelli $G$ et al. Sonography of the normal lung: Comparison between young and elderly subjects. J Clin Ultrasound JCU 2015; 43: 230-234

[34] Martelius L, Süvari L, Janér C et al. Lung Ultrasound and Static Lung Compliance during Postnatal Adaptation in Healthy Term Infants. Neonatology 2015; 108: 287-292

[35] Lichtenstein D, Meziere G, Biderman P et al. The comet-tail artifact: an ultrasound sign of alveolar-interstitial syndrome. Am J Respir Crit Care Med 1997; 156: $1640-1646$
[36] Volpicelli G, Mussa A, Garofalo G et al. Bedside lung ultrasound in the assessment of alveolar-interstitial syndrome. Am J Emerg Med 2006; 24 : 689-696

[37] Lo Giudice V, Bruni A, Corcioni E et al. Ultrasound in the evaluation of interstitial pneumonia. J Ultrasound 2008; 11: 30-38

[38] Lichtenstein D, Mezière G. A lung ultrasound sign allowing bedside distinction between pulmonary edema and COPD: the comet-tail artifact. Intensive Care Med 1998; 24: 1331 - 1334

[39] Volpicelli G, Cardinale L, Garofalo G et al. Usefulness of lung ultrasound in the bedside distinction between pulmonary edema and exacerbation of COPD. Emerg Radiol 2008; 15: 145-151

[40] Li H, Li YD, Zhu WW et al. High-Resolution Transthoracic Ultrasonography for Assessment of Pleural Lines in Patients With Dyspnea With CT Comparison: An Observational Study: High-Resolution TUS of Lung Pathology. J Ultrasound Med 2017; 36: 707-716

[41] Martelius L, Heldt H, Lauerma K. B-Lines on Pediatric Lung Sonography: Comparison With Computed Tomography. J Ultrasound Med 2016; 35: $153-157$

[42] Copetti R, Soldati G, Copetti P. Chest sonography: a useful tool to differentiate acute cardiogenic pulmonary edema from acute respiratory distress syndrome. Cardiovasc Ultrasound 2008; 6: 16

[43] Lichtenstein D, Mauriat P. Lung ultrasound in the critically ill neonate. Curr Pediatr Rev 2012; 8: 217-223

[44] Copetti R, Cattarossi L. The "double lung point": an ultrasound sign diagnostic of transient tachypnea of the newborn. Neonatology 2007; 91: $203-209$

[45] Zieleskiewicz L, Contargyris C, Brun C et al. Lung ultrasound predicts interstitial syndrome and hemodynamic profile in parturients with severe preeclampsia. Anesthesiology 2014; 120: 906 - 914

[46] Alzahrani SA, Al-Salamah MA, Al-Madani WH et al. Systematic review and meta-analysis for the use of ultrasound versus radiology in diagnosing of pneumonia. Crit Ultrasound J 2017; 9: 6

[47] Brito V, Niederman MS. Pneumonia complicating pregnancy. Clin Chest Med 2011; 32: $121-132$

[48] Di Marco F, Adelaide Roggi M, Terraneo S et al. Lung ultrasound as first line imaging tool in pregnant women with respiratory symptoms. Eur Respir J 2015; 46: OA494

[49] Riccabona M. Ultrasound of the chest in children (mediastinum excluded). Eur Radiol 2008; 18: 390 - 399

[50] Deganello A, Rafailidis V, Sellars ME et al. Intravenous and Intracavitary Use of Contrast-Enhanced Ultrasound in the Evaluation and Management of Complicated Pediatric Pneumonia. J Ultrasound Med Off J Am Inst Ultrasound Med 2017; 36: 1943 - 1954

[51] Gutierrez M, Gomez-Quiroz LE, Clavijo-Cornejo D et al. Ultrasound in the interstitial pulmonary fibrosis. Can it facilitate a best routine assessment in rheumatic disorders? Clin Rheumatol 2016; 35: 2387-2395

[52] Tardella M, Gutierrez M, Salaffi F et al. Ultrasound in the assessment of pulmonary fibrosis in connective tissue disorders: correlation with highresolution computed tomography. J Rheumatol 2012; 39: 1641-1647

[53] Sperandeo M, De Cata A, Molinaro F et al. Ultrasound signs of pulmonary fibrosis in systemic sclerosis as timely indicators for chest computed tomography. Scand J Rheumatol 2015; 44: 389-398

[54] Barskova T, Gargani L, Guiducci S et al. Lung ultrasound for the screening of interstitial lung disease in very early systemic sclerosis. Ann Rheum Dis 2013; 72: 390-395

[55] Gutierrez M, Salaffi F, Carotti M et al. Utility of a simplified ultrasound assessment to assess interstitial pulmonary fibrosis in connective tissue disorders - preliminary results. Arthritis Res Ther 2011; 13: R134

[56] Raso R, Tartarisco G, Matucci Cerinic M et al. A soft computing-based $B$-line analysis for objective classification of severity of pulmonary edema and fibrosis. JACC Cardiovasc Imaging 2015; 8: 495-496 
[57] Baria MR, Shahgholi L, Sorenson EJ et al. B-Mode Ultrasound Assessment of Diaphragm Structure and Function in Patients With COPD. Chest 2014; 146: 680-685

[58] He L, Zhang W, Zhang J et al. Diaphragmatic motion studied by M-mode ultrasonography in combined pulmonary fibrosis and emphysema. Lung 2014; 192: 553-561

[59] Zanforlin A, Smargiassi A, Inchingolo R et al. Ultrasound in obstructive lung diseases: the effect of airway obstruction on diaphragm kinetics. A short pictorial essay. J Ultrasound 2015; 18: 379-384

[60] Vilmann P, Clementsen P, Colella S et al. Combined endobronchial and esophageal endosonography for the diagnosis and staging of lung cancer: European Society of Gastrointestinal Endoscopy (ESGE) Guideline, in cooperation with the European Respiratory Society (ERS) and the European Society of Thoracic Surgeons (ESTS). Endoscopy 2015; 47: $545-$ 559

[61] Caroli G, Dell'Amore A, Cassanelli N et al. Accuracy of transthoracic ultrasound for the prediction of chest wall infiltration by lung cancer and of lung infiltration by chest wall tumours. Heart Lung Circ 2015; 24: $1020-1026$
[62] Wang S, Yang W, Zhang H et al. The Role of Contrast-Enhanced Ultrasound in Selection Indication and Improveing Diagnosis for Transthoracic Biopsy in Peripheral Pulmonary and Mediastinal Lesions. BioMed Res Int 2015; 2015: 1 -8

[63] Sperandeo M, Rea G, Grimaldi MA et al. Contrast-enhanced ultrasound does not discriminate between community acquired pneumonia and lung cancer. Thorax 2017; 72: 178 - 180

[64] Laursen CB, Naur TMH, Bodtger $U$ et al. Ultrasound-guided Lung Biopsy in the Hands of Respiratory Physicians: Diagnostic Yield and Complications in 215 Consecutive Patients in 3 Centers. J Bronchol Interv Pulmonol 2016; 23: 220-228

[65] Reissig A, Heyne JP, Kroegel C. Sonography of lung and pleura in pulmonary embolism: sonomorphologic characterization and comparison with spiral CT scanning. Chest 2001; 120: 1977-1983

[66] Mathis G, Blank W, Reissig A et al. Thoracic ultrasound for diagnosing pulmonary embolism: a prospective multicenter study of 352 patients. Chest 2005; 128: 1531-1538

[67] Bartelt S, Trenker C, Görg C et al. Contrast-enhanced ultrasound of embolic consolidations in patients with pulmonary embolism: A pilot study. J Clin Ultrasound JCU 2016; 44: 129-135 